\title{
10 Years vs. 16 Hours: An Effective Curriculum to Improve Chinese College Students' English Presentation Quality in Public
}

\author{
Wen Zhu ${ }^{1}$ \\ ${ }^{1}$ School of foreign language, Shanghai University of Engineering Science, China \\ Correspondence: Wen Zhu, School of foreign language, Shanghai University of Engineering Science, China.
}

Received: July 13, 2019 Accepted: August 18, 2019 Online Published: August 20, 2019

doi: 10.5539/elt.v12n9p82 URL: https://doi.org/10.5539/elt.v12n9p82

\begin{abstract}
Despite the long-term and intensive English learning educations they received, Chinese college students still have to struggle to make an even 2 minutes professional English presentation. Through more than 10 years English study, their vocabulary and language knowledge are enough for delivering an intermediate level English presentation. By observing a mid-sized (38 students) class study in details and one on one interviewing and surveying in Shanghai University of Engineering Science in 2014. The psychological factors are assumed to the top reason to hinder students from being confident and motivated in speaking English in public. A 16 hours task-based curriculum is designed with sufficient practices focusing on solving these psychologically related problems. Upon comparing and analyzing the detailed assessment data starting from the initial evaluation to the final examination, dramatically improved score and highly elevated sense of self achievement and satisfaction of the students were observed. It is evident the curriculum aimed on students' motivation and interests, as well as the 'hands-on' experiences should generate dramatic improvements for most of the Chinese college students.
\end{abstract}

Keywords: English learning, presentation, Chinese college students, self- confident, psychological factors

\section{Introduction}

Among the four macro English skills, speaking skills is the most important for communication, especially in the future career circumstances for college students, like job training, job interviews, etc. (Zaremba, 2006). Making a qualified English presentation is the ultimate purpose of learning English as a second language for most Chinese college students. Children in China are required to take English as the mandatory major courses since age of 7 , or even earlier (Cheng, 2010). In a regular school 8-hours schedule, English class is set at least 1.5 hours a day ranging from $1^{\text {st }}$ grade elementary school to $2^{\text {nd }}$ year undergraduate college. Even through those intensive English studying, and meeting the amount of English vocabulary around 5000, according to the CET test standard, Chinese college students still feel very challenging to deliver a proper English presentation in a relatively professional area in public ( $\mathrm{Lu} 2014)$.

In contrast, there are a lot of cases and live examples about young adults who can communicate smoothly for general talking in a complete new foreign language within a few months. It is quite common to see that the presentation skills of most of the foreign students, either in Chinese or English catch up dramatically, while neither of the two languages is their native tongues.

A general survey was given to 10 foreign exchanging students in Shanghai University of Engineering Science, asking them how they could learn to speak Chinese in a short period of time. Only 2 students said they attended certain language classes. The rest said they just learned from daily life and local people around.

Meanwhile, in China, the traditional English speaking class teaching style is instructor dominated: students have to spend at least half of the class time in listening to the teacher. Interaction is not encouraged. Practice opportunities are few for students. These caused the lack of interests, motivation and confidence in learning English speaking of these young adults.

If the newly designed curriculum focuses on stimulating students' interests, encouraging them to speak at their best, it probably will effectively help students to accelerate their presentation quality in a much shorter period.

\section{Initial Survey and Participants}

In order to explore why 10 years English learning did not build a qualified English speaker, the additional 
detailed survey was given to 263 college $1^{\text {st }}$ year students followed up with their evaluation presentation.

Among these 263 participants from various majors, 145 from Engineering majors, 24 from financial majors, 43 from management majors, 51 from visual arts design. There were 158 male students, 105 female students.

The initial evaluation presentation requires each student to give a 2 minutes or even short presentation facing around 30-40 classmates and 2 instructors as the audience. The topic assigned is 'The introduction of my major'. The PowerPoint slides were mandatory for the speech. The assessment sheet is designed as below:

Table 1. Initial presentation assessment items

\begin{tabular}{lc}
\hline Items for evaluations & score \\
\hline A. Content clearly presented & $10 \mathrm{pts}$. \\
B. Presentation well structured & $10 \mathrm{pts}$ \\
C. Pronunciation, tone control & $10 \mathrm{pts}$. \\
D. Proper manner and body language & $10 \mathrm{pts}$ \\
E. Is the presentation interesting, effective and attractive to audience (audience experience) & $10 \mathrm{pts}$. \\
Total & $50 \mathrm{pts}$. \\
\hline
\end{tabular}

All the 263 students participated into the presentation evaluation. The result of the initial presentation scores is as in Table 2.

Table 2. Initial presentation assessment score

\begin{tabular}{lll}
\hline item & $M$ & $S D$ \\
\hline A & 4.78 & 1.23 \\
B & 4.29 & 0.94 \\
C & 6.35 & 1.91 \\
D & 3.96 & 1.84 \\
E & 3.55 & 2.01 \\
\hline
\end{tabular}

From the result, it is obvious that these students are neither good nor comfortable at delivering speech in public, even in front of their familiar classmates.

An interview based survey was carried right after each presentation. The questions are:

a) Do you practice English speaking regularly?

b) What do you think is the biggest problem in English presentation

By collecting and arranging their answers, for question 1, the researcher finds that only 29 students among these 263 students said they practice English speaking regularly on various occasions. The practice occasions were reading books to themselves, participating weekly English salon, attending other English speaking classes. For question 2, it seems the psychological problems bothered these students much more than the language skills problems. The common problems for them are summarized in Table 3:

Table 3. The problems of presentation summarization

\begin{tabular}{ll}
\hline Psychological factors & Language skills \\
\hline 1) Very nervous at presentation, & $\begin{array}{l}\text { 1) Tend to copy the phrases on the books regardless of } \\
\text { the occasions }\end{array}$ \\
2) Afraid to face the audience & 2) Poor management of pronunciations, tone, gestures \\
3) Afraid to make mistakes, dare not to speak & and body languages, \\
4) Not confident nor comfortable at speaking &
\end{tabular}


These problems are very similar, almost identical to the psychological phenomenon in English speaking performing Ariyanti described in his research paper in 2014 (Ariyanti, 2014). Therefore, based on the strategy to release students from psychological shyness, anxiety, meanwhile, strengthen their motivations, confidence and self-esteem (Ariyanti, 2014), (Al Hosni, 2014), the curriculum specifically designed and tested for 5 months. The results are verified by comparing with the students' initial evaluation.

\section{Curriculum Designed and Participants}

The curriculum modules were finished on fall semester, 2015. 38 students chose to participate and take this curriculum instead of the traditional teacher- centered curriculum on the same semester. Among these 38 students, 15 are female students, 23 are male students. They are all from engineering majors. All the students voluntarily participated. Their initial evaluation scores are drawn and compared with the following presentation performance ratings.

The curriculum is aimed to release the student's negative psychological impacts on their speaking performance, as well as to encourage them to discover their presentation potentials and confidence at their maximum extent. There are 8 step by step modules including the final presentation exam.

\subsection{Module 1. Pronunciation Practice, Task based}

The purpose of the module 1 is to implant the correct pronunciation concepts of vowel and consonant; the appropriate tone of speaking short sentence pronunciation to the students. Each student is required to dictate a short 30 seconds speech of the TEDtalk video given by Prof. Robert Waldinger of Harvard University discussing about the 'Adult development Study' (https://www.ted.com/talks/robert_waldinger_what_makes_a_good_ life_lessons_from_the_longest_study_on_happiness?language=zh-cn). The reason to choose this video is that the presenter's stable, appropriate and soothing pronunciation and tone, as well as the ideas of Prof. Waldinger would be very beneficial to these young students facing their future life.

Each student is mandatorily required to recite and to be video recorded. All students completed this task. Though the speaking time was only around 30 seconds each student, the average time each student spent on practicing was around 1 hour. 29 of the 38 students achieved great improvement with the rate above 8 of 10 . Upon their own feedback, 35 of 38 students said they benefited from this module while 21 of them said this module greatly helped them to improve how to pronounce.

\subsection{Module 2.Communication, Tone, Gestures Practice. Task based}

The purpose of the module 2 is to get students released from their anxiety of speaking another foreign language, familiarize them with the cultural difference so that they can express their emotions fluently with appropriate tones, gestures and other body language indications. One short 90 seconds movie clip was selected from the movie 'Zootopia'. Students were grouped into a 3 person team to perform the conversation of the play for 'Officer Hops', 'Fox Nick' and 'Belwether'.

Students were asked to relax and enjoy the fun of the communicating in English talking and dramatic body language. Script reading is strictly not allowed, for students could not focus on their talking and communicating by sight distraction. All students completed this task (while one student performed twice for the number of 38 students into 13 groups).

37 of 38 Students' feedback stated this module greatly stimulated their interest in speaking English. All students achieved the good rate above 7 of 10, while 31 of 38 achieved above 8 of 10.35 students stated that this module was very helpful for them to connect the language, tone and body movement gestures naturally and directly. They used to translate what they thought into English and read it instead.

\subsection{Module 3.A 2 Minutes Easy Presentation With Topics Assigned, Task Based}

The purpose of the module 3 is to get students ready for delivering a serious presentation. Each student was required to give a presentation about 'My university life' (or other self-related topics) individually. Slides were mandatory. Reading is strictly not allowed. Since this topic is highly personalized. Students had to make the presentation by their own words, which enabled them to express their own idea fluently. The minimum length of this presentation was 2 minutes 3 slides. Video recording was served for each presenter.

These 38 students all finished the presentation and reviewed their recorded video. Though the average rate of this task was 6.87 of 10, 27 of 38 students stated that they felt less nervous, with more confidence and relaxed and positive psychological status. 


\subsection{Module 4. A 3 Minutes Presentation for Describing a New Product, Task Based}

The purpose of the module 4 is to get students prepared to make a clear, well-structured presentation to describe accurately about a specific stuff. The task was aimed to get the students to learn and bear in mind that they should make their best efforts to enable the audience have a clear and correct understanding of what they present in the shortest time.

Students were required to watch a video introducing a newly invented ultrasound washer called 'Dofi'. Then they need to introduce this product to another class who were unfamiliar with this 'Dofi' individually. Slides were mandatorily needed. The evaluation rate is combined with $60 \%$ from the instructors and $40 \%$ from the audience.

Due to the fact of the unfamiliar audience, students stated they spent much more efforts than the previous modules. During the presentation, constant interactions occurred between audience and presenter. Students had demonstrated high motivations in the process.

The result from their motivated presentation was encouraging; the average evaluation rate they achieved from the instructors was 4.87 of 6 and 3.12 of 4 from the audience.

\subsection{Module 6. A Group Presentation for Introducing an Eco Project, Task Based}

The purpose of the module 6 is to get students prepared for a real project presentation. The 38 students were divided into 10 groups, 3 to 4 students per group. They need to clearly and effectively introduce a real Eco project to the audience. The eco project was about the idea of 'use the leaf food containers for green, no more plastic ones'. Slides were mandatorily required. Students mimic the real project pitch with video recording.

The green leaf food container project was illustrated to students in documents and product brochures. Students should turn them into a well-organized straightforward and vivid presentation. The evaluation is solely given by the 2 instructors.

After the presentation, 36 of the 38 students' feedbacks stated that the practice was very helpful for them to learn the real world project presentation. 26 of the 38 students stated they enjoyed the practice. 31 of the 38 students achieved above 7 of 10 .

\subsection{Module 7. Final Examination}

Final examination enabled both students and instructors to view the results of this 16 hours training. Each student was required to deliver a serious academic presentation. Students can pick topic out of their own interest with presentation duration of no less than 3 minutes. Slides were mandatorily required with video recording.

All these 38 students took the final examination. The evaluation items were exactly identical to the initial presentation for comparison. The detailed evaluation and advices were explained and discussed individually after their exam in person.

\section{Results}

The results of this module rely on comparing the performance of the students before and after the 16 hours course. Each evaluation column is independently compared by the paired 2 tails $t$ tests.

A) Content clearly presented

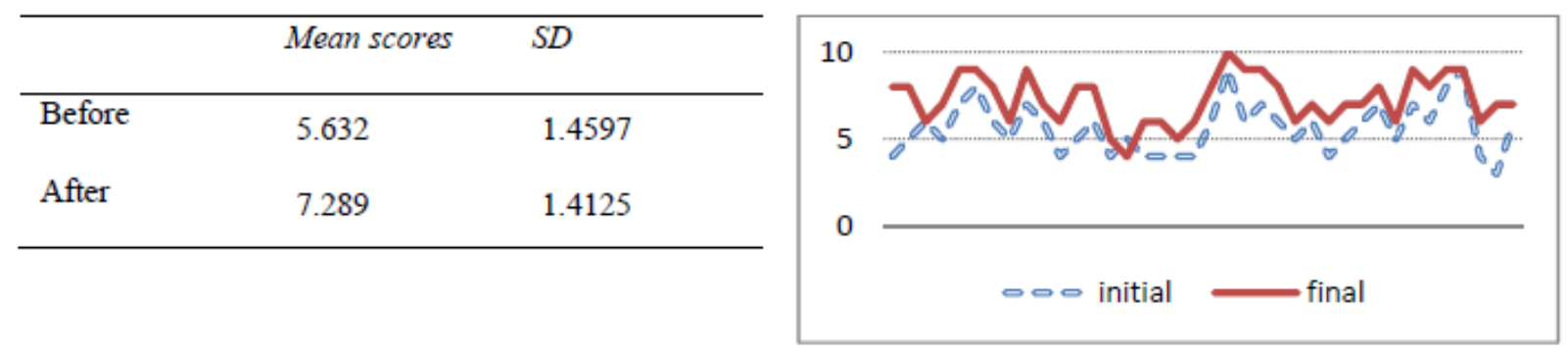

The results of the $t$ test is: $t(37)=-10.28, p<0.001$. It states that the difference is significant for of the scores for 'how to present the content clearly'. 
B) If the presentation is well-structured

\begin{tabular}{lll}
\hline & Mean scores & $S D$ \\
\hline Before & 5.612 & 1.3528 \\
After & 7.026 & 1.5852 \\
\hline
\end{tabular}

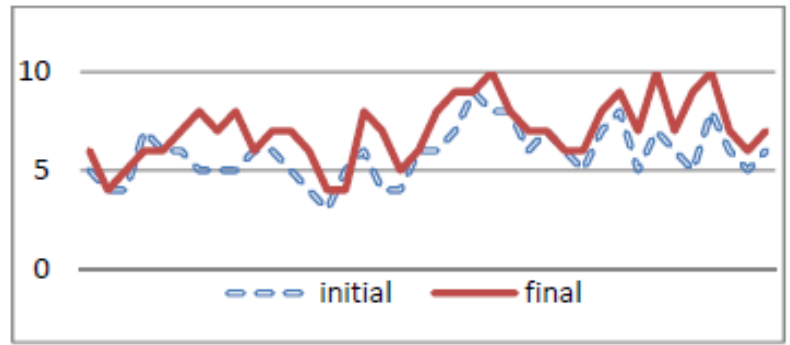

The results of the $t$ test is: $t(37)=-6.53, p<0.001$. It states that the difference is significant for of the scores for 'if the presentation is well-structure'.

C) Pronunciations and tone control

\begin{tabular}{lll}
\hline & Mean scores & $S D$ \\
\hline Before & 5.974 & 1.7932 \\
After & 6.974 & 1.7780 \\
\hline
\end{tabular}

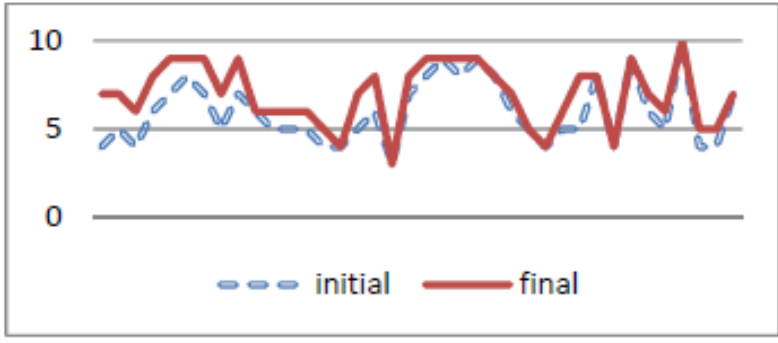

The results of the $t$ test is: $t(37)=-6.85, p<0.001$. It states that the difference is significant for of the scores for 'pronunciations and tone control'

D) Proper manner and body language

\begin{tabular}{lll}
\hline & Mean scores & $S D$ \\
\hline Before & 5.053 & 2.2172 \\
After & 7.105 & 1.9423 \\
\hline
\end{tabular}

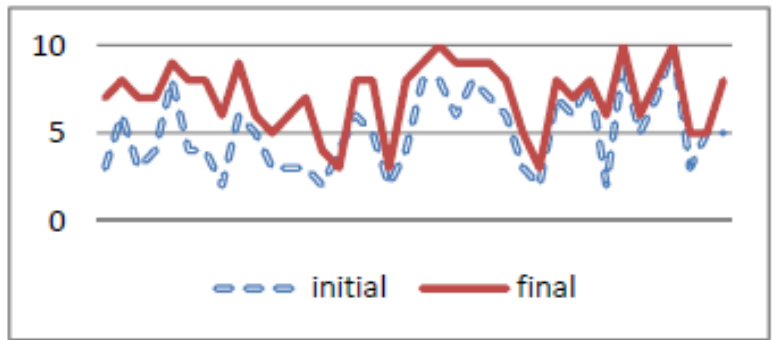

The results of the $t$ test is: $t(37)=-9.206, p<0.001$. It states that the difference is significant for of the scores for 'if the presentation is well-structure'

E) The speech is effective or attractive (audience experiences)

\begin{tabular}{lll}
\hline & Mean scores & $S D$ \\
\hline Before & 5.407 & 1.7812 \\
After & 7.000 & 1.7708 \\
\hline
\end{tabular}

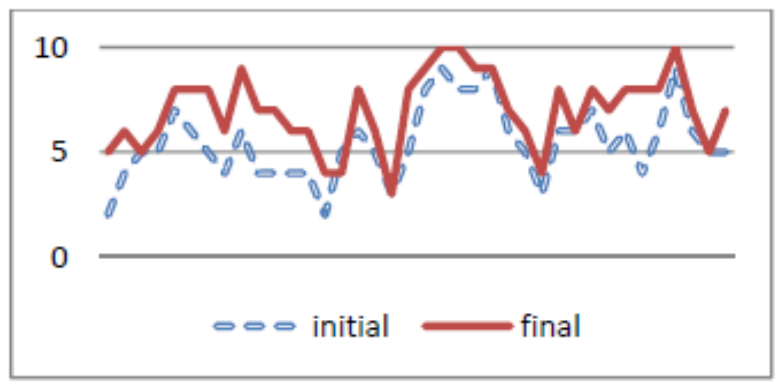

The results of the $t$ test is: $t(37)=-8.803, p<0.001$. It states that the difference is significant for of the scores for 'if the presentation is well-structure' 


\section{Discussion}

The comparison of the scores shows a significant difference between the evaluation of the students' first presentation and their final examination presentations. Among these 5 categories, 'well-structured presentation' seems to be the one improved least which stands at $\mathrm{t}(37)=-6.53$. A well-structured presentation requires logical organization about the contents of the presentation, as well as the read-proof work. According to students' own feedbacks, many of them are reluctant to review their presentation slides. Most of the boy students said they found difficult to present their ideas through rich examples. The $2^{\text {nd }}$ least improved category is 'pronunciation and tone control', which the mean value increased from $5 / 97$ to 6.97 . the $t(37)=-6.85$. It is understandable as these students' age is over 18 years. Pronunciation habits are hard to change for adults, despite that the students were willing to make efforts to improve their pronunciations.

'Content clearly presented' is the category students achieved most, $t(37)=-10.28$ 'manner and body language' is the category students achieved greatly, $\mathrm{t}(37)=-9.26$. Students said in their feedback that they had great interests in watching and improving their body languages and manners. They are willing to spend review their videos to improve 'how they look like'.

Through examining the evaluation rates students had at their very first and the final examinations, the improvements in all these 5 aspects are obvious. From the students' own statements and the instructors' observations, students were greatly motivated by this kind of modules, which related the skills and real application scenarios closely. Besides, the video recording is also a very useful tool to encourage students to present their potentials. Every student did review their own recordings after the presentation. It greatly helps them to improve efficiently and effectively. During the 16 hours process, they stated they felt very motivated about each task. They were willing to spend efforts and time to achieve the positive feedback from the audience.

\section{Conclusions}

The ultimate purpose of the language is to communicate ideas not only for the test. When students were released from the worries of making mistakes, they demonstrated much more motivation and interest in learning to speak English. Any curriculums focusing on building up their confidences and relating closely with the real word professional scenarios would benefit the students a lot.

Like language, presentation is never the work only limited to the throat and tongue; it involves the whole body and appropriate attitude to deliver a clear and effective one to make the audience accept the speaker's idea smoothly. This curriculum does not follow the regular English speaking courses on grammars and accuracy. It intends to motivate the students by accomplishing the tasks and getting the feedback of their performances immediately from audience and the video recordings. Upon the feedback and the observations from this group of students, the curriculums of English speaking learning which provide the students the Hands-on practice opportunity, rather than listening to the instructor and mimic would be encouraging and beneficial to these college students in China.

\section{Reference}

Al, H. (2014). Speaking Difficulties Encountered by Young EFL Learners. International Journal on Studies in English Language and Literature (IJSELL), 2(6).

Ariyanti. (2016). Psychological Factors Affecting EFL Students'Speaking Performance. ASIAN TEFL, I(1). https://doi.org/10.21462/asiantefl.v1i1.14

Cheng, L., \& Curtis, A. (2010). English language assessment and the Chinese learner. New York: Routledge: Taylor's \& Francis Group

Lu J., Woodcock, S., \& Jiang, H. (2014). Investigation of Chinese University Students' Attributions of English Language Learning. SAGE. https://doi.org/10.1177/2158244014562391

Zaremba, A. J. (2006). Speaking professionally. Canada: Thompson South-Wester

\section{Copyrights}

Copyright for this article is retained by the author(s), with first publication rights granted to the journal.

This is an open-access article distributed under the terms and conditions of the Creative Commons Attribution license (http://creativecommons.org/licenses/by/4.0/). 